\title{
A vertigem do tempo na História do Cerco de Lisboa, de José Saramago ${ }^{1}$
}

\author{
Marcílio França Castro \\ Universidade Federal de Minas Gerais
}

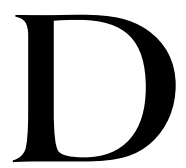

a varanda da casa do revisor Raimundo Silva, na Rua do Milagre de Santo Antônio, tem-se uma visão privilegiada - e duplicada - da cidade de Lisboa. Sob nevoeiros constantes, que dividem a paisagem em sombra e luz, pode-se, num primeiro olhar, que pinta aproximadamente o final do século XX, observar da janela o Tejo, a igreja da Sé e suas torres, os telhados das casas descendo em degraus até o leito do rio. Pode-se ainda perceber o murmúrio de turistas que vem das ruas da Baixa, um cineasta que arrasta uma cena qualquer ou um bonde elétrico deixando seu ruído na curva da Madalena.

Em outra perspectiva, quando o olhar vindo da janela mergulha no passado, a paisagem que se vê, tão presente e sensível quanto a primeira, às vezes retransformando-se nela, é a da Lisboa do século XII. Nesse quadro, o prédio do revisor é uma torre moura e tem a função de proteger a Alfofa, uma das cinco portas que dão acesso ao interior da cidade cercada por uma muralha. Para quem observa de cima, no lugar das casas, surgem arrabaldes e soldados e, no lugar da Sé, cresce a almádena de uma mesquita, de onde um almuadem lança o seu grito - Allabu akbar chamando os fiéis para a oração.

Esse duplo cenário, no qual se tece a História do Cerco de Lisboa, de José Saramago, pode ser tomado como a face mais visível de um fibroso labirinto temporal que o romance configura. Entre imagens e palavras desdobradas - os séculos, a cidade, os amores, o texto - a narrativa

\footnotetext{
${ }^{1}$ Este ensaio apresenta, em linhas gerais, o estudo desenvolvido pelo autor em sua dissertação de Mestrado (2001).
} 
desenha e confunde o tempo em múltiplas dimensões, paralelas, atravessadas, difusas, cujas formas muitas vezes não se deixam reconciliar.

O romance de Saramago merece ser lido, conforme pretende este ensaio, como um campo de expressão estética de temporalidades variadas. Em tal perspectiva, importam menos a revisitação ou a possível reconstrução do passado histórico português a que a narrativa remete; interessam antes as formas de expansão e percepção do presente que a ficção sugere, a abertura do tempo a novas fruições, o esboço de uma improvável subjetividade.

Entre o discurso e o imaginário ficcional, é possível recortar no romance figurações temporais em perspectivas variadas. No plano da escrita, por exemplo, tomada em sua materialidade, corre um tempo à flor do texto, como efeito do próprio fluxo discursivo, do arranjo peculiar das frases - a pontuação, o ritmo - na narrativa. No campo da representação ficcional, abrem-se janelas para tempos históricos, que mostram o século XX e o século XII, mas também evocam, na paisagem multifacetada de Lisboa, signos esparsos de várias outras épocas. Nesse trânsito, o narrador plasticamente captura, para si e para o leitor, um tempo-lugar específico, a um só tempo memorial (porque tem o domínio de vários tempos) e presente (onde todos os tempos se enunciam). Em outra vertente, arrastando os acontecimentos, flui um tempo do devir, que move e consome as personagens, pelo acaso e pela experimentação. Por um território difuso (uma teia), salta um tempo vertiginoso, no qual um instante perturbador é capaz de comunicar universos, abrir o sujeito de um deles à sensação do de outro. E, por fim, enredando a todo instante a ficção e a história, há um tempo do sonho, que reata Saramago a uma possível tradição da cultura portuguesa, na qual essas duas dimensões convergem para compor um gênero singular - o onírico -, de certo modo prefigurado pelo argentino Jorge Luis Borges. ${ }^{2}$

\section{A letra sagrada: um prólogo quase teatral}

Algumas questões fundamentais sobre o tempo na História do Cerco são anunciadas já no capítulo de abertura do romance. De inspiração filosófica e dramática, o texto consiste em um diálogo entre um historiador

${ }^{2}$ Veja-se o ensaio de Borges sobre o pesadelo em Sete Noites (1999, p. 242-255). 
e um revisor e se apresenta como um prólogo quase teatral, sem marcação cronológica, em contraste com os tempos históricos e com a narratividade dos capítulos seguintes. Os dois interlocutores expõem suas impressões sobre a criação, o tempo e a escrita; sobre a importância de emendar e corrigir; sobre a precariedade da verdade; sobre os vínculos entre a vida, a história, as artes e a literatura. Nesse debate, um jogo de temporalidades em tensão se revela, opondo o eterno e o transitório, o divino e o humano, o predeterminado e o casual, o único e o plural.

Em tom bíblico, quase profético, o colóquio, de modo irônico, instala o revisor e o historiador no conforto de um tempo em suspensão. Esse tempo, em que as vozes dos anjos estão livres das correntes da história (não há duração), deve contrastar com o tempo humano, marcado pela transitoriedade e pela finitude.

O discurso irônico - estrategicamente encenado - desestabiliza os conceitos de dogma e verdade, de autoridade e hierarquia, de causalidade e determinismo, de prefiguração e linearidade. Parece ser a própria concepção cristã de tempo, genericamente considerada, que está aqui subliminarmente em discussão: a visão neotestamentária de um tempo linear, progressivo e contínuo, uno e irrevogável, submetido aos planos de Deus, do qual trata Germano Pattaro em texto recolhido por Paul Ricoeur. ${ }^{3}$ As linhas desse tempo, enraizado nas tradições cristãs, podem ser tomadas como uma espécie de contraponto para o tempo ficcional que a História do Cerco de Lisboa reverbera.

As concepções de tempo e história erigidas em torno de uma verdade monolítica qualquer tendem a inibir as criações singulares da temporalidade, as que exploram as fendas, as partes secretas, as exceções, os resíduos - e os erros. É em função disso que o revisor, no debate com o historiador, aponta a rasura como uma fórmula decisiva para a criação. Afirmando ironicamente que "o trabalho de emendar é o único que nunca se acabará no mundo", sugere que é preciso refazer e desmembrar, a cada passo, o percurso da vida como se aditam e se transformam os textos,

\footnotetext{
${ }^{3}$ Segundo Pattaro, "encontramos na consciência do Cristianismo a certeza de que tanto o homem como a humanidade vivem a intervenção ativa de Deus a seu respeito. Essa intervenção deve ser comprendida não no sentido cosmológico, como uma intervenção sobre as coisas, mas no sentido antropológico, como uma intervenção na história do homem." (1980, p. 201).
} 
infinitamente. Cada movimento desse jogo imprevisível - cuja finalidade é o próprio jogo - inventa um universo novo, em um tempo que surpreende, sem apagar o anterior.

Raimundo Silva, como um Lúcifer que trai a obra de seu criador, irá assim modificar uma história supostamente fechada. No século XX, ao revisar um livro que narra o episódio do cerco e da tomada de Lisboa aos mouros por tropas cristãs no ano de 1147, adultera-lhe uma passagem: os cruzados europeus, em trânsito pela cidade a caminho da Terra Santa, passam a dizer não, ao invés de sim, à convocação feita por D. Afonso Henriques, rei de Portugal, para que auxiliem as suas tropas na batalha contra os mouros. A intervenção desafia a dogmática divina por meio da escrita. É na escrita que vai eclodir o tempo sempre imperfeito, emendável, casual, multíplice e aberto da criação: "Porque os tempos deixaram de ser noite de si mesmos quando as pessoas começaram a escrever, ou a emendar, torno a dizer, que é obra doutro requinte e outra transfiguração". (p. 13)

Deve-se perceber como a ironia produzida na abertura do romance dá uma volta sobre si mesma, tal qual a serpente que iria engolir a própria cauda e desiste no momento final (o traço do deleatur). Se os signos proféticos que inervam esse prólogo servem ao mecanismo de desconstrução do cânone, é também a partir deles que se projeta um gesto filosófico tendente a escapar à própria ironia: o de devolver à literatura, porém às avessas, a sacralidade subtraída da tradição: "em minha discreta opinião, senhor doutor, tudo quanto não for vida, é literatura”, diz o revisor. (p. 15).

E é exatamente o tempo ficcional, com sua potência inventiva e transformadora, que vai assomar à condição de tempo sagrado. Se a escrita inaugura o tempo, a literatura é anterior a ela, ou mais, "a literatura já existia antes de ter nascido” (p. 15). Saramago, ao pôr a ficção no lugar da escritura divina (onde tudo se prefigura), cria uma relação invertida: a literatura imprime um caráter casual ao sagrado. O tempo profético (dogmático) é substituído por uma outra promessa (profana): a dos tempos múltiplos e imprevisíveis. 


\section{Os tempos que se bifurcam}

Um tempo imaginário, como duplo do real, agrega signos das mais diferentes categorias. É flexível, imprevisto, sujeito à variedade de formas e à invenção. Pode moldar-se por referências cronológicas, por acontecimentos da natureza, por símbolos e marcas culturais; pode também, como nos contos de fada, estar fora do calendário, pode ser embaçado ou vazio. Pode associar-se a épocas históricas ou a processos psicológicos, pode constituir a experiência de uma personagem. Pode associar-se a um rito, uma repetição, uma mitologia. Pode ainda alongarse ou contrair-se, avançar e retroceder, suspender-se, multiplicar-se; pode ser reto ou circular, uno ou múltiplo, realista ou fantástico. Pode, também, dobrar-se sobre a narrativa e representar o tempo da escrita.

Em todos esses casos, o tempo imaginário, com sua "infinita docilidade" (Benedito Nunes), mesmo que fragmentado, obscuro ou auto-referencial, instaura-se na esfera da representação e remete às infinitas imagens que uma forma de memória qualquer (individual, coletiva ou difusa) é capaz de transformar em narrativa. Mesmo esse tempo da história, mimético por definição, pode reter certos flancos, certos paradoxos interiores, que, nas dobras do discurso, respiram formas de temporalidade para além da representação. Assim como a vida se recobre de impressões selvagens, ou de absurdos que uma lógica submetida à estabilidade não consegue perceber, também o mundo aparentemente costurado da mimese pode em certos casos avançar para a não-compreensão, para o campo de puras intensidades.

$\mathrm{Na}$ História do Cerco, o ato transgressor de Raimundo Silva bifurca no tempo não apenas a história de Portugal, mas também a sua própria, e a de outros personagens, como Maria Sara, e suas narrativas parciais se entrelaçam e se confundem. Duas séries temporais principais assim se desenvolvem, confrontando a época contemporânea com a medieval dois blocos de espaço-tempo. Na primeira delas, os acontecimentos impõem uma temporalidade cronológica (ao mesmo tempo vivida e destruída) a Raimundo Silva: o encaminhamento da cópia modificada à editora, a expectativa, em "treze longos e arrastados dias", da descoberta da alteração, a conversa com o diretor literário e o primeiro contato com Maria Sara; a proposta dela de reescrita da História do Cerco, o jogo de aproximação entre os dois, os movimentos da criação literária e o enlace amoroso. A série medieval, por sua vez, costura uma versão para a conquista 
de Lisboa alternativa à dos documentos oficiais, como a da carta de Osberno: ${ }^{4}$ a recusa dos cruzados, a permanência de alguns deles no Tejo, os debates sobre a possível batalha, as investidas contra a cidade, o ataque final.

Tais séries, correndo paralelas, ora se alternam, ora se cruzam, ora se dividem ou se fundem. Podem vincular-se ao movimento de uma personagem ou escapar dela, podem tornar-se uma sombra. Podem corresponder a um processo subjetivo (um pensamento, um sonho), uma cronologia, uma seqüência de gestos. Cada uma das séries pode ramificarse em subséries, pode agregar-se a uma outra e dilatar-se, pode manterse isolada. E se constroem numa fronteira sempre embaçada entre o vivido e o sonhado, o eu e o outro, a escrita e a vida.

Seria importante chamar a atenção, neste ponto, para um traço marcante das personagens da História do Cerco, bem como de personagens centrais de outros romances de Saramago: a carência de espessura psicológica, a sua leveza móvel, que não as deixa constituírem-se como personalidades acabadas e as faz reagir à unidade, à estagnação, ao limite. Não é atributo de Raimundo Silva, por exemplo, a formação psicológica ou a carnadura moral. Apesar de incorporar, pelo trabalho, uma identidade social, esta não lhe garante uma natureza, não o supõe um ser dado. Ao contrário, uma subjetividade flui nele a partir dos movimentos que executa, de suas dúvidas, afetos, decisões. Os acontecimentos que o consomem são os mesmos que, no presente, o constituem; por isso é preciso abri-los, multiplicá-los, buscar neles as brechas de uma evasão. O sujeito aí se constrói no percurso da narrativa, no ato do discurso, pela descoberta, pela experimentação. Figura-se nesse processo uma quaseimpessoalidade, sem nostalgia, sem remorso, de alguém que se move em direção ao desconhecido (tal como o sr. José, de Todos os nomes).

Essa forma de subjetivação, que proclama um presente incessante e aberto, parece aproximar-se daquilo que Alain Badiou descreveu como um processo de "ruptura continuada":

\footnotetext{
${ }^{4}$ Carta, de autoria discutível, escrita por um certo cruzado inglês, que teria sido testemunha do evento histórico. A esse respeito, convém conferir o texto da Conquista de Lisboa aos mouros em 1147 - Carta de um cruzado inglês.

${ }_{5}$ BADIOU, 1994. p. 110-111.
} 
O sujeito não preexiste de forma alguma ao processo.Ele é absolutamente inexistente na situação antes do evento. Dir-se-á que o processo de verdade induz um sujeito. [...] O "sujeito", assim concebido, é diferente do sujeito psicológico, do sujeito reflexivo (no sentido de Descartes) ou do sujeito transcendental (no sentido de Kant). Por exemplo, o sujeito induzido pela fidelidade a um encontro amoroso, o sujeito do amor, não é o sujeito amante descrito pelos moralistas clássicos. Porque tal "sujeito" psicológico concerne à natureza humana, à lógica das paixões. Ao passo que aquilo de que falamos não tem nenhuma preexistência "natural".

É nesse sentido que a narrativa de Saramago não se ocupa da representação de um passado pessoal. De Raimundo Silva, "o que mais nos interessa é o presente, e, se do passado uma lembrança, muito menos o seu do que, do passado geral, a parte modificada pela palavra impertinente" (p. 65). O tempo que atravessa as personagens do romance jamais será proustiano, porque o passado que emerge nelas já não é mais passado - nem individual, nem psicológico — é um presente invisível; e a possível recordação já nem existe, porque não se trata mais de lembrarse de si próprio, mas sim do outro. Resvala, no sujeito dessa ficção, a sensação do outro, a transubjetividade.

\section{O sonho português}

É recorrente na História do Cerco o embaçamento das margens internas da narrativa, de suas instâncias, de suas dicções. É o que ocorre com os relatos fragmentados entretecidos na narrativa geral - a história paralela que Raimundo Silva escreve, a crônica de D. Afonso Henriques, a carta de Frei Rogeiro a Osberno ou o livro dos milagres de Santo Antônio -, com as vozes da narrativa - como a do narrador e a de Raimundo Silva, a do Costa e a de Maria Sara -, com os planos temporais, os focos narrativos - a onisciência, a intrusão, o diálogo, o comentário, a digressão - e, ainda, com as dimensões do narrado, do sonhado e do vivido, da história e da ficção.

Para além dessas interseções, a ficção de Saramago apropria-se ainda de certos registros de sonhos, lendários na história de Portugal, que aparecem em documentos de época e que eventualmente já foram objeto de abordagens ficcionais. É o caso do festejado sonho de Dom Afonso Henriques com Cristo antes da batalha de Ourique (o milagre versejado por Camões), do sonho de Ega Moniz com Santa Maria, que lhe ordena 
a edificação de uma igreja, e ainda dos sonhos de um cruzado com o cavaleiro Henrique, morto em batalha. Todos esses sonhos aparecem descritos, como episódios históricos, na Crónica de El-Rei D. Afonso Henriques, de Duarte Galvão, para citar, como exemplo, um documento fonte da historiografia de Portugal.

Eduardo Lourenço, ao escrever sobre o tempo português, associouo à saudade e ao sonho, levando em conta a sensibilidade particular dos portugueses para a fusão de paisagens: ${ }^{6}$

Contrariamente à lenda, o povo português, ferido como tantos outros por tragédias reais na sua vida coletiva, não é um povo trágico. Está aquém ou além da tragédia. A sua maneira espontânea de se voltar para o passado em geral, e para o seu em particular, não é nostálgica e ainda menos melancólica. É simplesmente saudosa, enraizada com uma tal intensidade no que ama, quer dizer, no que é, que um olhar para o passado no que isso supõe de verdadeiro afastamento de si, uma adesão efetiva ao presente como sua condição, é mais da ordem do sonho que do real. É esse lugar de sonho, esse lugar ao abrigo do sonho, esse passadopresente, que a "alma portuguesa" não quer abandonar.

Ultrapassando a dicotomia entre a escrita histórica e a ficcional, a narrativa do sonho cria, na História do Cerco, o seu tempo próprio, que se comunica, em versão fantástica, ainda que irônica, com o labirinto mítico, por que não dizer sebastianista, da literatura portuguesa.

\section{O tempo da vertigem: diálogos com Borges}

A brincadeira de desdobrar o tempo em várias dimensões nos permite enxergar a ficção de Saramago à luz do universo temporal que, no Jardim dos caminhos que se bifurcam, Borges concebeu. Nesse conto, o jardim apresenta-se como um enigma sobre o tempo, proposto pelo sábio chinês Ts'ui Pen, cuja decifração estaria em um romance caótico, de enredo paradoxal, feito de histórias e tempos alternativos ou excludentes, mas simultaneamente realizados.

Não é difícil conceber, assim, que o romance de Saramago, pela sua arquitetura, de certo modo abriga o projeto de Ts'ui Pen. Ambos remetem

\footnotetext{
${ }^{6}$ LOURENÇO, 1982. p. 14.
} 
à idéia de um labirinto temporal, que, no conhecido preceito borgeano, compreenderia "infinitas séries de tempos, numa rede crescente e vertiginosa de tempos divergentes, convergentes e paralelos." Talvez fosse apropriado, no contexto contemporâneo, usar o termo bipertempo para conceituar essa máquina cósmica de "tempos que se aproximam, se bifurcam, se cortam ou que secularmente se ignoram".

A comparação entre os textos dos dois autores, que evidentemente não tem caráter especular, pode levar-nos a uma formulação instigante, apesar de artificiosa: o tempo que em Borges comparece como uma insinuação ou um projeto ficcional, em Saramago constitui, mesmo que diferenciadamente, um modo de narrar e de representar, uma trama cheia, um processo discursivo. Nesse sentido, importa dizer que o texto de Saramago (como em Kafka e seus precursores) não apenas interpreta o de Borges, mas também o amplia, dando nova abertura às leituras que dele se possam fazer. A ficção de um se reconhece na do outro, e Saramago, ao traduzir Borges (e, inevitavelmente, traí-lo), elege-o como ensaísta virtual de seu romance.

Mas é preciso avançar um pouco mais na visão desse tempo multíplice, para percebê-lo na sua incômoda microscopia. Quero com isto assinalar os traços que se insinuam, tanto no Jardim quanto na História do Cerco, de um outro tempo mais sutil, que subjaz ao desenho dos tempos simultâneos e os transfigura. Trata-se de um tempo difuso e quase invisível, cuja imagem, apenas intuída, provém do encontro de séries temporais ou blocos de espaço-tempo presumidamente inconciliáveis entre si: os tempos incompossíveis, nos termos de Gilles Deleuze, ou os que, numa perspectiva linear, por se sucederem, não podem coexistir.

Se a interseção de duas séries compossíveis produz um acontecimento, a de duas séries incompossíveis produz uma vertigem: o resultado de uma ligeira e perturbadora sincronicidade. Vislumbrar esse tempo absurdo pode ser o mesmo que capturar um raio no exato instante em que sua luz revela as linhas ocultas que formam uma constelação.

Assim é que, na história de Borges, o universo de mundos bifurcados atravessa o narrador, insistentemente, sob a forma de uma intangivel pululação, "não a pululação dos divergentes, paralelos e finalmente

\footnotetext{
7 BORGES, 1998. p. 532-533.

${ }^{8}$ BORGES, 1998. p. 532.
} 
coalescentes exércitos, mas uma agitação mais inacessível, mais íntima e que eles, de certo modo, prefiguravam". ${ }^{9}$ Este parece ser o sinal de um tempo múltiplo em que todas as combinações de histórias são possíveis: mesmo as que se negam ou, por contradição, se aniquilam.

$\mathrm{Na}$ História do Cerco, o passado coexiste com o presente e o presente se distende; o falso concorre com o verdadeiro, mas não o abole. Uma seqüência imprevista de cintilações deslocam a personagem (ou o seu outro), transitoriamente, para um tempo vertiginoso: "o mundo, então reemendado, terá vivido diferentemente só um curto instante" (p. 51). Raimundo Silva é acometido por impressões que ele não sabe exatamente de onde vêm (de que tempo, de quem?) e que não têm explicação. Um súbito silêncio, a dor de um soco na boca do estômago, o ladrar de um cão, um recorrente mal-estar são sensações que lembram as pululações no jardim de Ts'ui Pen.

Se, na potência da multiplicidade, as histórias de Borges e de Saramago criam um sujeito dividido em tempos simultâneos, nelas também se vê, paradoxalmente, o instante em que sujeitos diferentes parecem compartilhar um momento absoluto.

Tome-se uma imagem preciosa para a narrativa da História do Cerco: a do grito do almuadem, chamando os fiéis para a oração. Se ela parece surgir, no romance de Saramago, como um signo colado ao espaçotempo medieval e muçulmano, na verdade nesse cenário não se contém, nem a ele pertence exclusivamente. Vigoroso, foge aos muros da cidade moura até alcançar o acampamento cristão e ecoar nos ouvidos do soldado que (tal como nas crônicas da época) se chama Mogueime, este que sonha, antes da batalha, com a galega cujo nome (tal qual a amante de Amadis de Gaula) é Ouroana.

Como a lança que fere dois homens num só instante, o mesmo grito, oito séculos depois, ressoa sincronicamente na cabeça de Raimundo Silva, que a um só tempo narra e pressente, em si e no outro, o amor e a morte. Dividido entre a ficção que ele constrói e a invenção na qual, como personagem, é construído, o revisor reparte com Mogueime a quasemesma dor e a quase-mesma mulher, no momento em que o grito do almuadem os atravessa:

\footnotetext{
${ }^{9}$ BORGES, 1998. p. 531.
} 
"uma voz ouvida nas trevas, a sua, ou, porventura, a daquele Outro que não sabe mais que repetir as palavras que vamos inventando, estas com que tentamos dizer tudo, bendição e maldição, até o que nome não terá nunca, inominável" (p. 29).

Esse grito também está em Borges: sua repetição difusa lembra, num jogo de simetrias simples, as variações do patético gemido de César no instante em que o punhal de Bruto o atinge de modo fatal, descritas num breve conto do escritor argentino chamado $A$ trama.${ }^{10} \mathrm{O}$ mesmo efeito se nota em Martín Fierro, história que põe em cena o retorno de um duelo de facas entre gaúchos de gerações distintas, como reafirmação das "vicissitudes comuns e de certo modo eternas que são a matéria da arte"."

O grito de morte, a sombra incessante de um objeto, a face solitária de um cão, uma rosa - imagens recorrentes em várias narrativas de Saramago - compõem um universo de formas e figuras cuja existência vale por si mesma e não se prende à sua circunstância nem ao sujeito que a dimensiona. São geometrias que se repetem sem jamais se mostrarem de todo, como o traço condensado de um presságio ou uma brevíssima ilusão. Jorge Luis Borges traduziu magistralmente esse recorte ficcional da realidade como a iminência de uma revelação. Segundo ele, "essa iminência de uma revelação, que não se produz, é talvez o fato estético". ${ }^{12}$

De modo análogo, o próprio Borges evoca, em vários outros textos, a descoberta da repetição como meio assombroso de romper com a linearidade do tempo e fundir num só espasmo, próximo da eternidade, duas situações coincidentes ocorridas em épocas e lugares distintos. A existência de certos momentos impessoais e autônomos prevaleceria sobre os processos temporais subjetivos, fazendo desmoronar os próprios conceitos de tempo e sujeito.

À infinidade de séries temporais, ao hipertempo, as ficções de Borges e Saramago opõem, concomitantemente, o instante elementar, a própria negação das séries do tempo. Afinal, "não basta um único termo repetido para desbaratar e confundir a série do tempo?", ${ }^{13}$ diz Borges. Ou,

\footnotetext{
${ }^{10}$ BORGES, 1999. v. 2, p. 191.

${ }^{11}$ BORGES, 1999. v. 2, p. 195.

${ }^{12}$ BORGES, 1999. v. 2, p. 11.

13 BORGES, 1999. v.2, p. 157.
} 
ainda: "todos os homens, no vertiginoso instante do coito, são o mesmo homem. Todos os homens que repetem uma linha de Shakespeare são William Shakespeare." 14

Entre o múltiplo e o uno, o tempo mostra uma dupla face: a da faísca de séries que se cruzam; a da coalescência de instantes que se aglutinam. Entretanto, no jogo casual das relações do tempo com o outro surge uma terceira temporalidade: o tempo transubjetivo. Prolongar-se no tempo é, nessa perspectiva, prolongar-se no outro, e a experiência ficcional da História do Cerco abre à luz essa delicada possibilidade. Nesse mundo, o sujeito não é soberano (como o dos românticos), não está fragmentado (como o dos modernistas), não está vazio: está refeito em flutuações, sem no entanto, ainda que como sombra, deixar de existir - individualidade e transubjetividade.

Na visão duplicada de Lisboa, como o olhar que se refrata para além de um espesso bloco de vidro, a hierarquia entre os tempos se dissolve, e o presente perde o seu privilégio sobre o passado. Assim, o ato de alguém narrar - no campo real ou imaginário, não importa - a história de outro num suposto passado significa mover, no presente, a peça de sua própria história. Por outro lado, efetuar, a cada instante, um movimento no presente significa mudar ou criar, simultaneamente, algo no passado. É através desses movimentos que se torna importante, não, recuperar o passado, mas, sim, através dele, e até mesmo de seus simulacros, revelar certos aspectos invisíveis do próprio presente.

${ }^{14}$ BORGES, 1999. v. 2, p. 483. 


\section{Referências Bibliográficas}

BADIOU, Alain. Para uma nova teoria do sujeito. Rio de Janeiro: RelumeDumará, 1994.

BORGES, Jorge Luis. Ficções. In: Obras Completas. São Paulo: Globo, 1998. v.1.

BORGES, Jorge Luis. Outras inquisições. In: - Obras Completas. São Paulo: Globo, 1999. v.2.

BORGES, Jorge Luis. O fazedor. In: . Obras Completas. São Paulo: Globo, 1999. v.2.

BORGES, Jorge Luis. Sete Noites. In: Obras Completas. São Paulo: Globo, 1999. v.3.

CASTRO, Marcílio França. O tempo da vertigem na ficção de José Saramago. 2001. Dissertação (Mestrado em Estudos Literários) - Universidade Federal de Minas Gerais, Faculdade de Letras, Belo Horizonte.

Conquista de Lisboa aos mouros em 1147. Carta de um cruzado inglês. Lisboa: Livros Horizonte, 1989.

DELEUZE, Gilles. Lógica do sentido. São Paulo: Perspectiva, 1994.

LOURENÇO, Eduardo. Mitologia da Saudade. São Paulo: Companhia das Letras, 1999.

PATTARO, Germano. A concepção cristã do tempo. In: RICOEUR, Paul (Org.). As culturas e o tempo. Petrópolis: Vozes; São Paulo: Ed. da USP, 1975.

RICOEUR, Paul (Org.). As culturas e o tempo. Petrópolis: Vozes; São Paulo: Ed. da USP, 1975.

SARAMAgO, José. História do Cerco de Lisboa. São Paulo: Companhia das Letras, 1990. 


\section{Resumo}

Este trabalho procura investigar as formas de expressão do tempo na narrativa da História do Cerco de Lisboa, de José Saramago. Elegendo Jorge Luis Borges como interlocutor privilegiado de Saramago, o estudo tenta mostrar como a ficção da História do Cerco pode traduzir, nas teias da sua multiplicidade, a experiência de um hipertempo e ainda evocar, nas imagens da sincronicidade, o tempo da vertigem.

\section{Abstract}

This is an investigating work on the ways of expressing time in Historia do cerco de Lisboa narrative, by José Saramago. Choosing Jorge Luis Borges as a privileged interlocutor of Saramago, this work tries to show how the fiction in História do Cerco is able to translate, in the nets of multiplicity, the experience of bypertime and also to evoke, through images of sincronicity, the vertiginous time. 